Nova Biologica Reperta 7(3): 267-277 (2020)

Print ISSN: 2423-6330/Online ISSN: 2476-7115
يافته هاى نوين در علوم زيستى

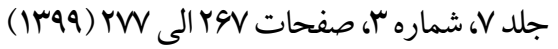

انتشارات دانشگاه خوارزمى

$$
\begin{aligned}
& \text { اثر عصاره شاهدانه در آسيب القايى ميدانهاى الكترومغناطيسى بر بلوغ فوليكولهاى } \\
& \text { تخمدانى و تغييرات سطح هورمونى در موش كوجك آزمايشعاهى }
\end{aligned}
$$

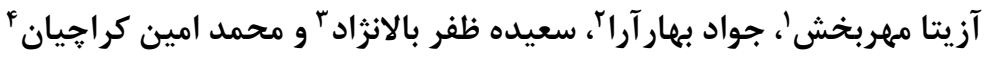

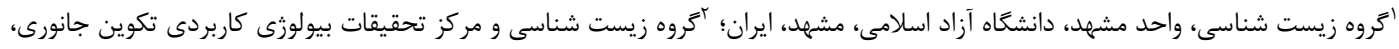

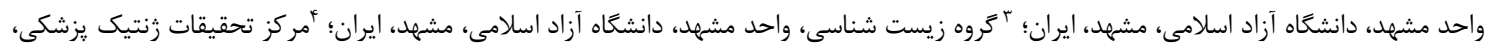

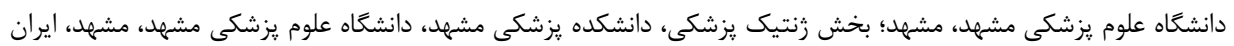

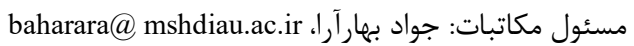

جكيده. امواج الكترومغناطيسى (EMF) تركيبى از امواج الكتريكى و مغناطيسى هستند. انرزى حمل شده به وسيله اين تابشها در بافتهاى زنده جذب مىشود.

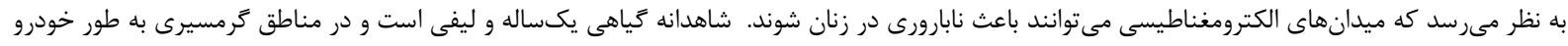

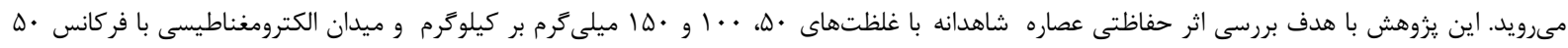

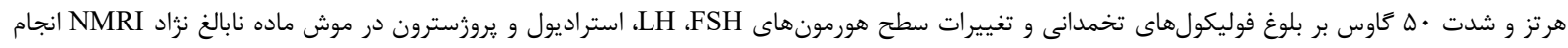

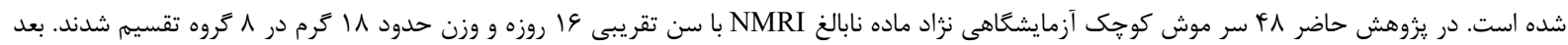

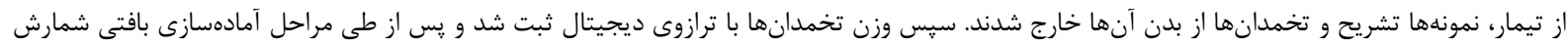

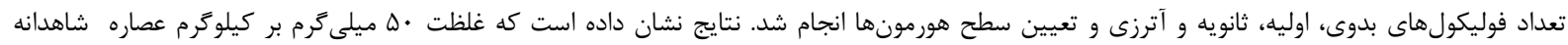

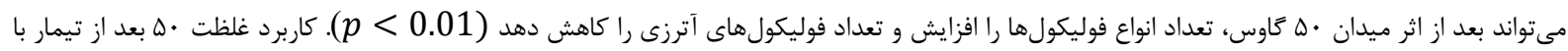

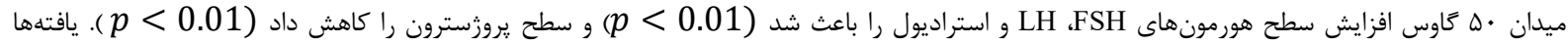

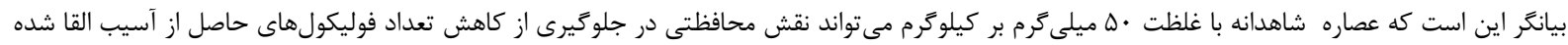
توسط امواج الكترومغناطيسى داشته باشد.

وازههاى كليدى. شدت ميدان، شمارش فوليكولها، نابارورى، نزاد NMRI، وزن تخمدان

\title{
The effect of Cannabis sativa extract on damages induced by electromagnetic fields on ovarian follicle maturation and hormonal surface changes in mice
}

Azita Mehrbakhsh ${ }^{1}$, Javad Baharara ${ }^{2}$, Saeedeh Zafar Balanejad ${ }^{3}$ \& Mohammad Amin Kerachian ${ }^{4}$

${ }^{1}$ Department of Biology, Mashhad Branch, Islamic Azad University, Mashhad, Iran; ${ }^{2}$ Department of Biology \& Research Center for Animal Development \& Applied Biology, Mashhad Branch, Islamic Azad University, Mashhad, Iran; ${ }^{3}$ Department of Biology, Mashhad Branch, Islamic Azad University, Mashhad, Iran; ${ }^{4}$ Medical Genetics Research

Center, Mashhad University of Medical Sciences, Mashhad; Department of Medical Genetics, Faculty of Medicine,

Mashhad University of Medical Sciences, Mashhad, Iran

Correspondent author: Javad Baharara, baharara@mshdiau.ac.ir

\begin{abstract}
Electromagnetic waves (EMF) are a mixture of electrical and magnetic waves. The energy transmitted by these radiations is absorbed by living tissues. Electromagnetic fields seem to cause infertility in women. Cannabis is annual herbaceous plant grows in tropical areas. This study was conducted to investigate the protective effects of hydroalcoholic extract of Cannabis sativa in various doses of 50,100 and $150 \mathrm{mg} / \mathrm{kg}$ on the damages induced by electromagnetic fields of $50 \mathrm{~Hz}$ and 50 Gauss, on the puberty of ovarian follicles and levels of FSH, LH, estradiol and progesterone hormones in NMRI immature mice. In this study, 48 NMRI immature female mice with an approximate age of 16 days and approximate weight of 18 grams were divided into 8 (experimental, sham, positive control and negative control) groups. After the treatment, the ovaries were extracted and weighed, and sections with H\& E staining,
\end{abstract}


the number of primordial, primary, secondary, and atretic follicles were counted, and the level of hormones have been done. The results showed that the concentration of $50 \mathrm{mg} / \mathrm{kg}$ of cannabis extract after the exposure to electromagnetic field of 50 Gauss could increase the number of follicles and reduce the number of atresia follicles $(p<0.01)$. The group treated with the concentration of $50 \mathrm{mg} / \mathrm{kg}$ of cannabis extract after the exposure to electromagnetic field of 50 Gauss showed increased levels of FSH, LH and estradiol hormones $(\mathrm{p}<0.01)$ and a reduced level of progesterone $(\mathrm{p}<0.01)$. Therefore, the concentration of $50 \mathrm{mg} / \mathrm{kg}$ of cannabis extract have a protective role in preventing infertility due to ovarian tissue damages induced by electromagnetic fields.

Key words. field intensity, follicle count, infertility, NMRI, ovary weight

مجموع نقصهاى زمان تولد، سقط جنين و تولد بيش از موعد را باعث

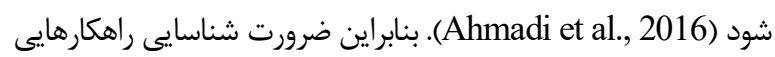

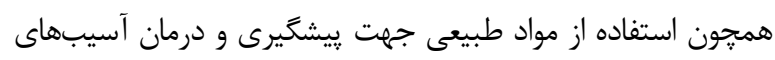

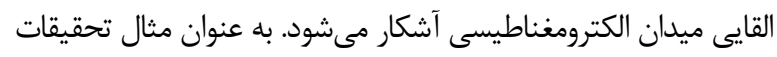

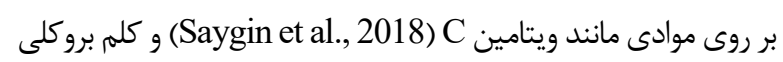
نقش حفاظتى آنها در برابر ميدانهاى (Mansouri et al., 2019)

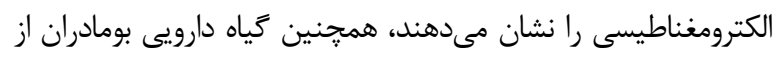

تركيبات فعال زيستى غنى است (Baharara et al., 2019).

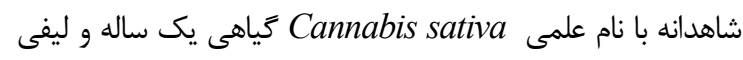
است و در مناطق گرمسيرى به طور خودرو مىرويد و از اين گياه تاكنون

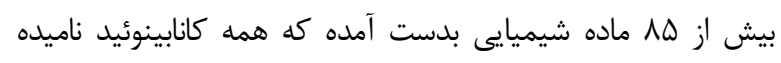

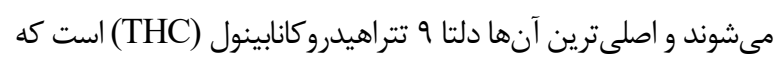

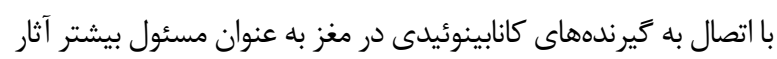

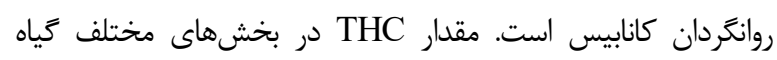

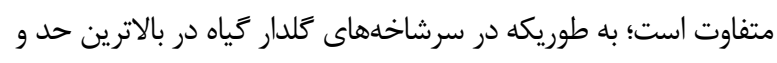

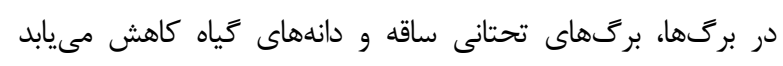
(Tehranipour et al., 2012) تأثير تركيبات مختلف عصاره شاهدانه شديدا به مقدار و مدت مصرف بآ.

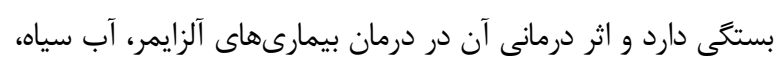

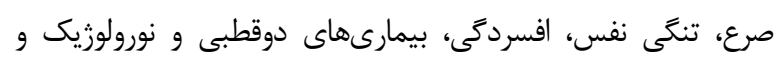

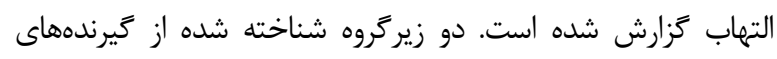

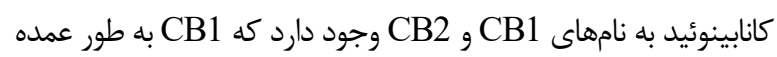

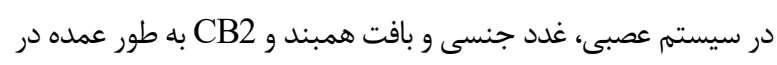

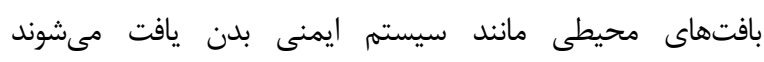

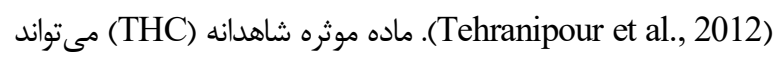

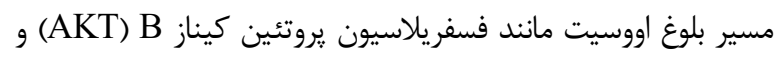

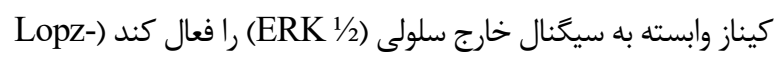

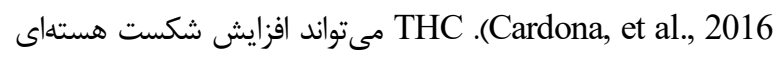

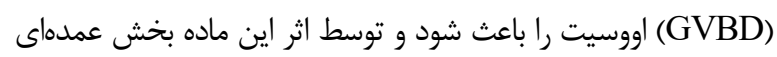

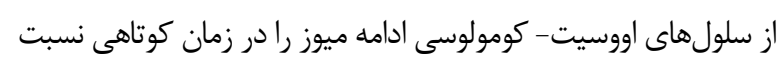

به حالت طبيعى از سر مى كيرند (Campen et al., 2017).

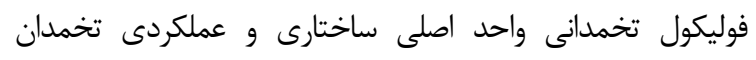

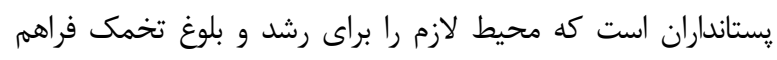

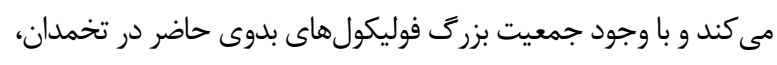

\section{مقله}

امواج الكترومغناطيسى (EMF) تركيبى از امواج الكتريكى و مغناطيسى هستند كه در خلأ با سرعت نور جريان مى البابند و فرمى از از

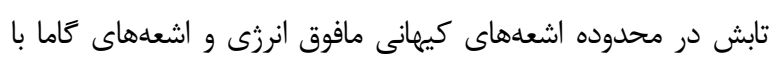

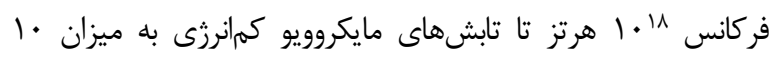

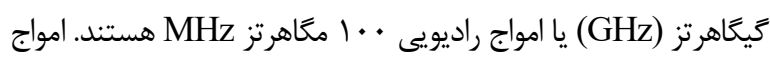

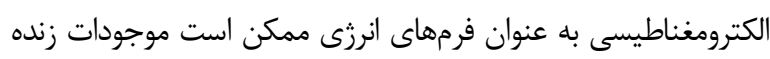

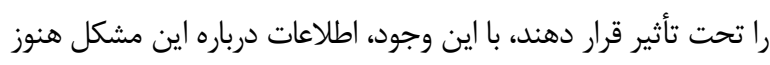

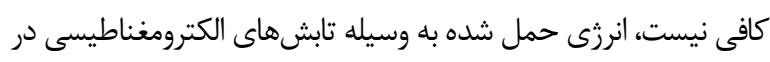

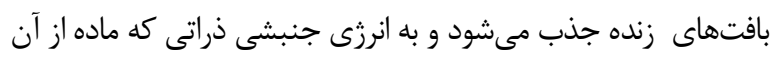

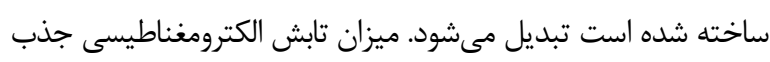

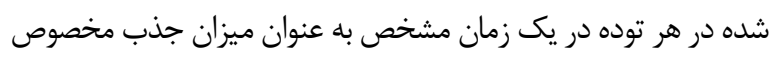
Specific Absorption Rate (SAR)

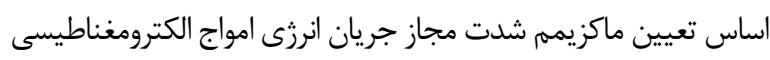

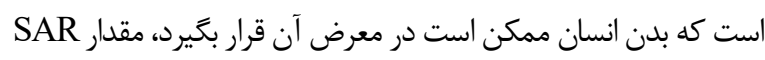

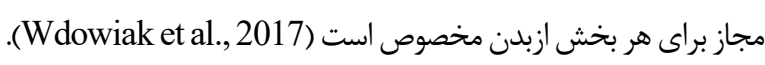

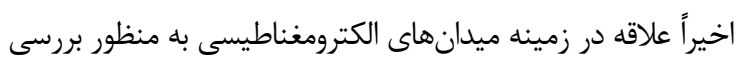

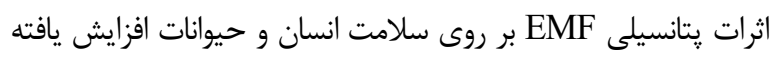

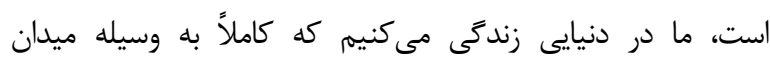
رنومغناطيس زمين با شدت الكترومغناطيسى به وسيله منبع ساخت انسانى ايجاد شده است. اثرات

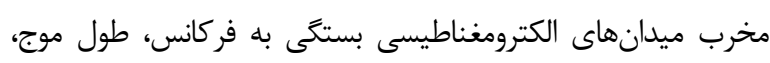

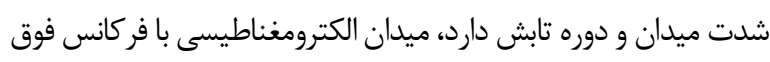

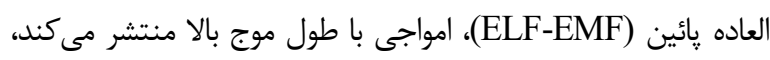

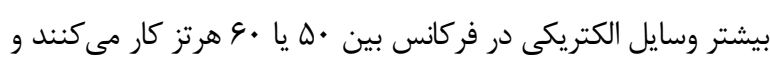

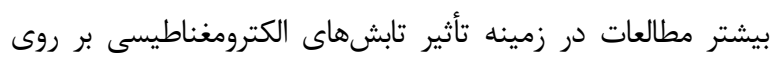

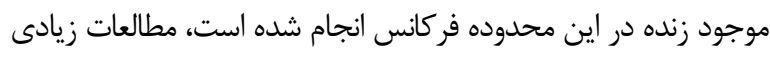

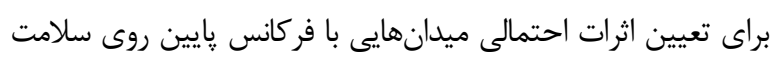

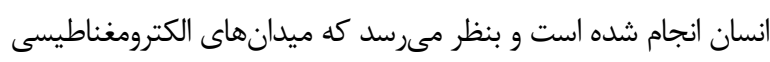

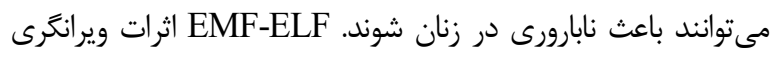

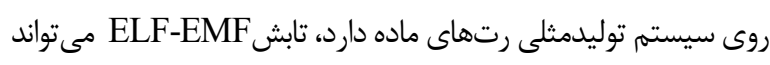
تغييراتى در بافت رحم و تخمدان رت ايجاد كند، تعداد بلاستوسيستها

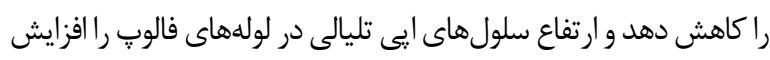

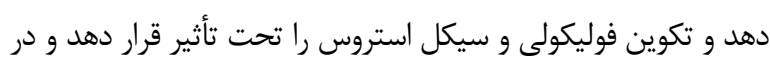




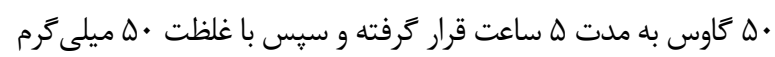
بر كيلوكرم عصاره شاهدانه تيمار شدند.

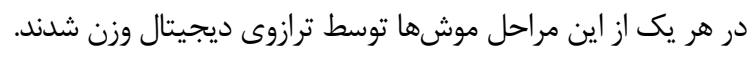

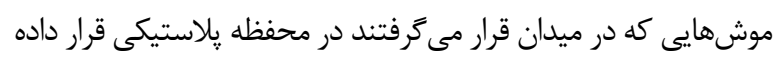

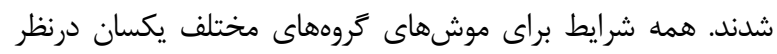

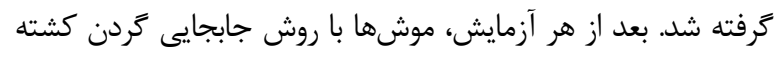

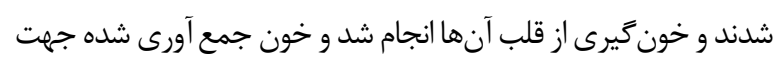

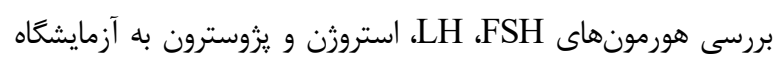

تشخيص طبى فردوس مشهد تحويل و مورد بررسى قرار ترفت

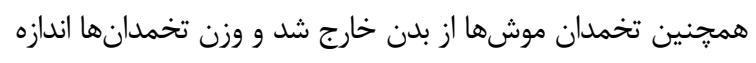

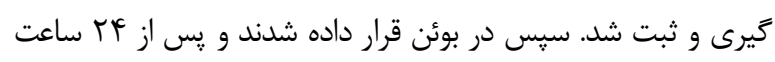

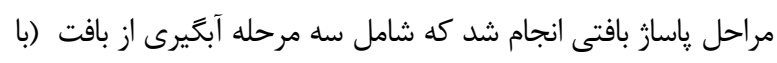

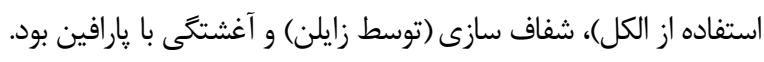

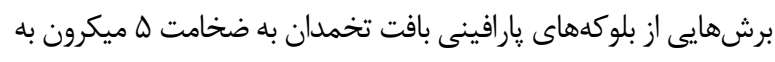

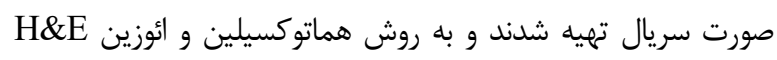

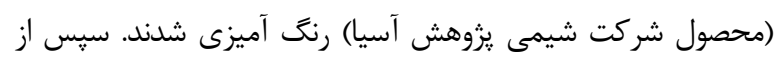

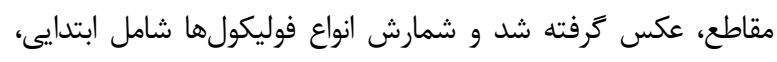

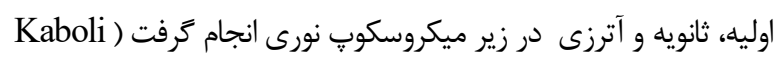

(Kafshgiri et al., 2017

نتايج كمى حاصل توسط آزمونهاى آمارى t، ANOVA

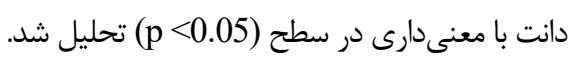

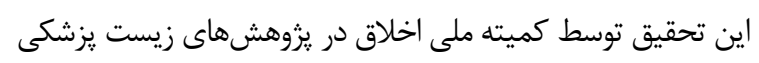

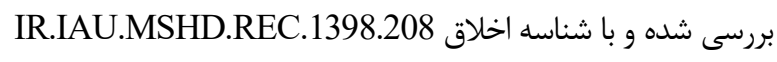
مصوب كرديده است.

نتايج نتايج حاصل از بررسى غلظتهاى مختلف عصاره شاهدانه بر بلوغ فوليكولهاى تخمدانى و تغييرات سطح هورمونهاى FSH لتائل

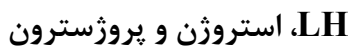

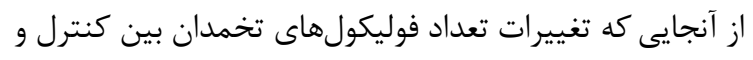

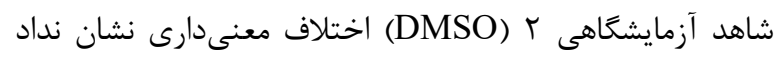
مقاطع (p) 0.05$)$

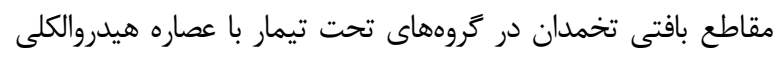

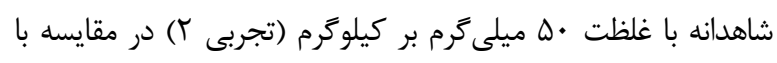

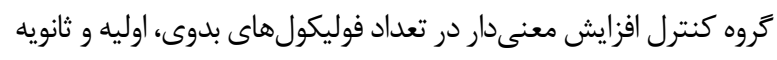

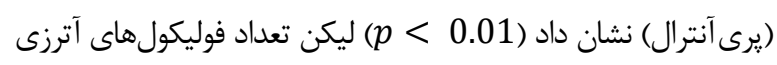

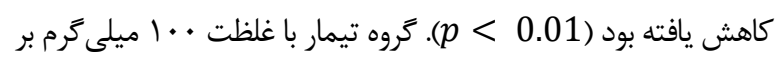

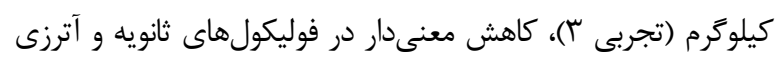

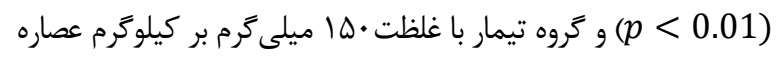

در طى فوليكولوزنز تعداد بسيارى از فوليكولها دجار آترزى شده و تعداد

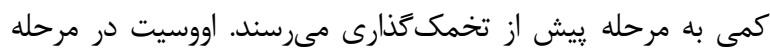

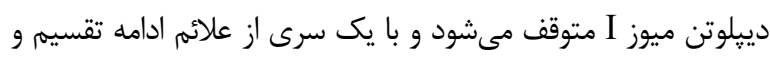

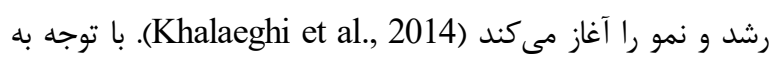
مصرف اين گياه در يزشكى و با توجه به اينكه تاكنون تحقيقى در زمينه

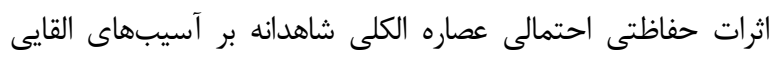

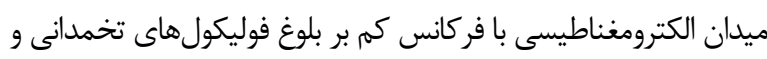

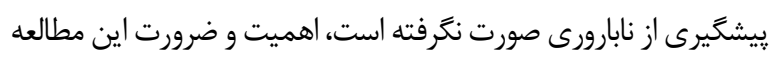
آشكار مىشود.

مواد و روش ها

در بروهش حاضر 14 سر موش كوجى آزمايشكاهى نزاد ماده نابالغ

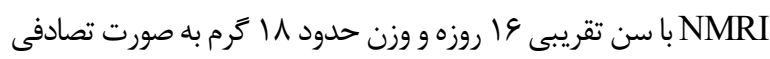

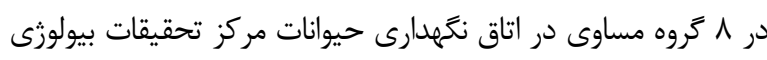

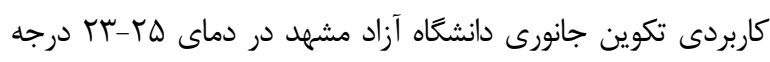

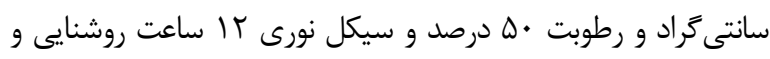

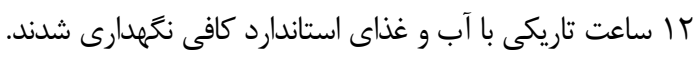

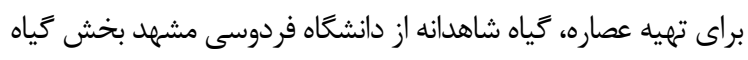

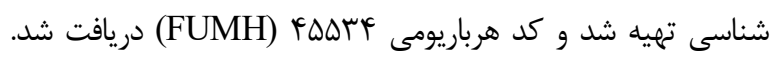

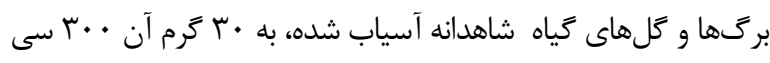

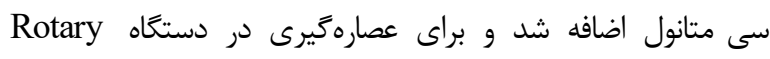
Evaporator براى خشك شدن قرار كرفت (Farrokhyar et al., 2015).

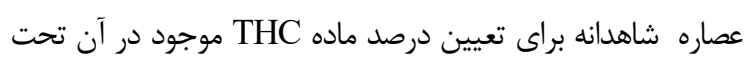

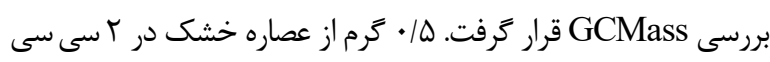

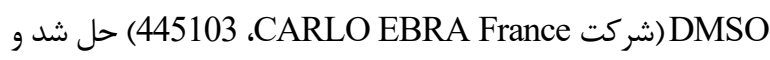
طيف كروماتوكرافى بررسى شد. ماده مورد نظر ما كه THC بود

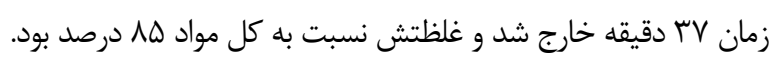

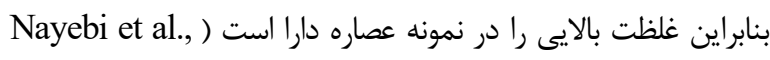

موشها در كروه كنترل، تحت هيج گَونه تيمارى قرار نكرفتند. كروه

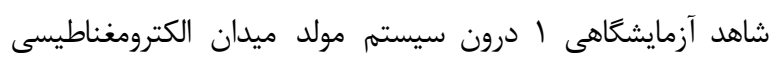
خاموش قرار داده شدند. سيستم مولد ميدان الكترومغناطيسى دانشعاه آزاد اسلامى مشهد توسط محققان طراحى شده است ( Baharara et

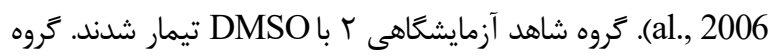

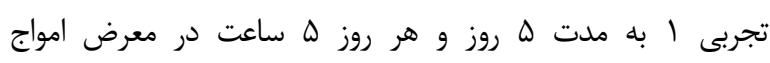

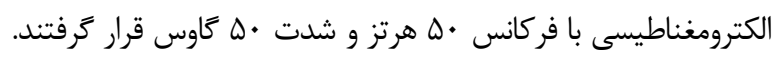

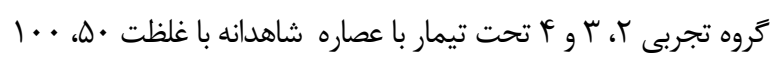

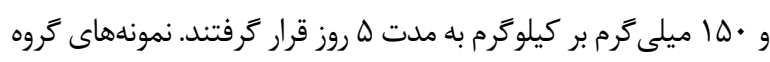

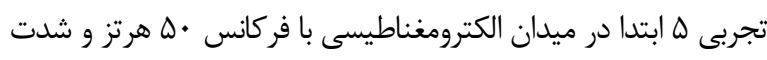


A
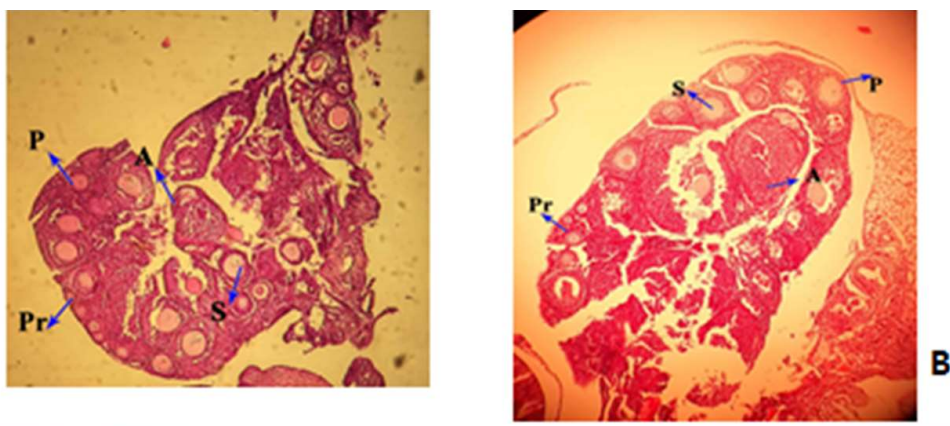

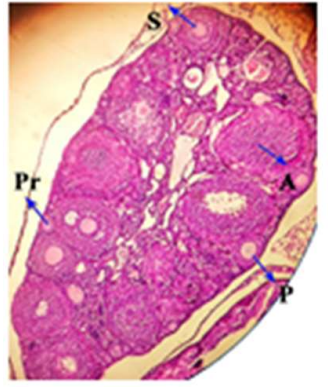

C

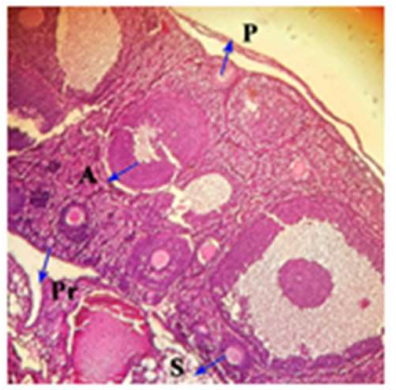

D

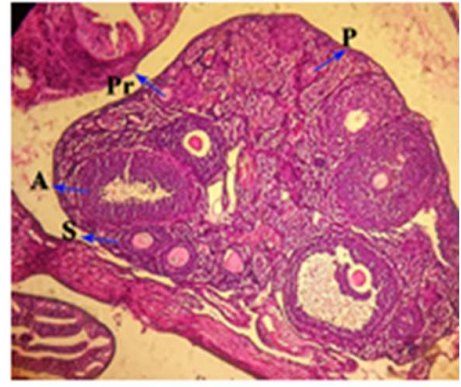

E

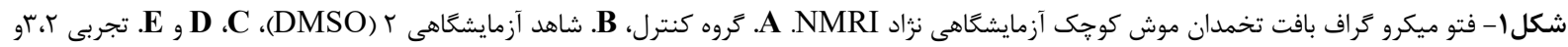

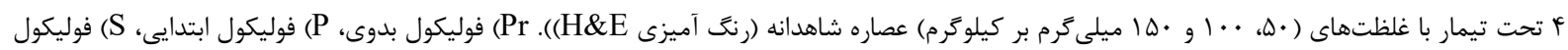

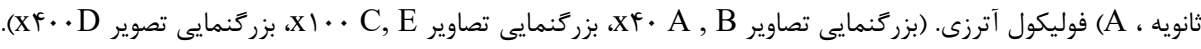

Fig. 1. Photo micrograph of ovarian tissue. A. control, B. DMSO, C, D \& E. experimental 2, 3 \& 4 treated with concentrations $(50,100$ and $150 \mathrm{mg} / \mathrm{kg}$ ) of Cannabis extract (H \& E)). Pr) Primordial follicle, P) Primary follicle, S) Secondary follicle, A) Atresia follicle (images A,B zoom in x40, images C,E zoom in x100,image D zoom in x400).

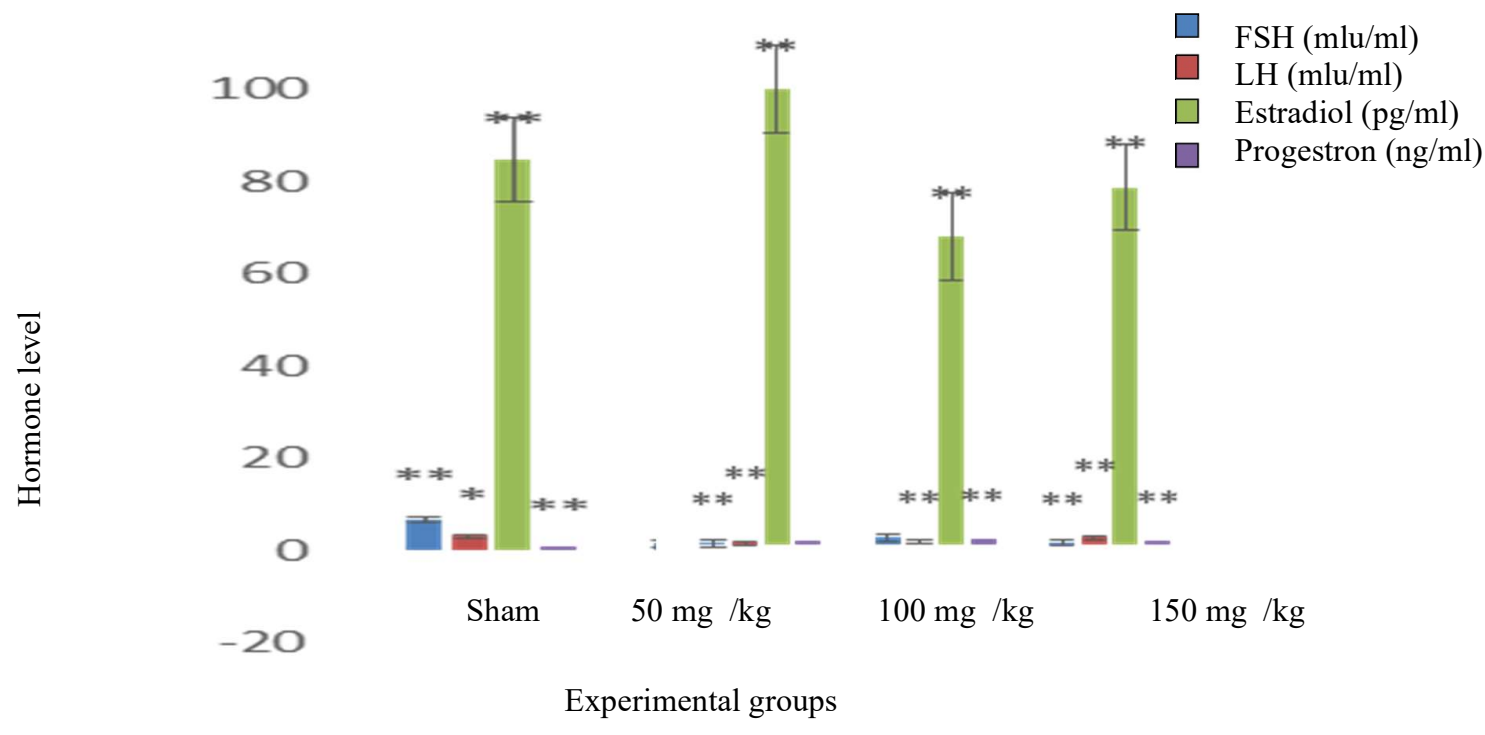

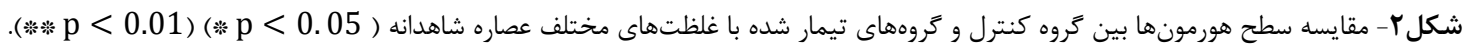

Fig. 2. Comparison of the steroid hormone levels among control and different concentrations of cannabis extract $(* p$ $<0.05)(* * \mathrm{p}<0.01)$. 
نتايج حاصل از كاربرد توام عصاره شاهدانه با غلظت •ه و

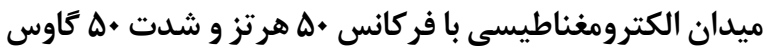
بر بلوغ فوليكولها و تغييرات سطح هورمونها

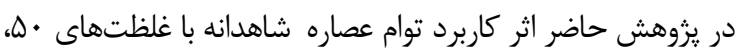

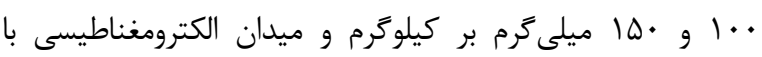

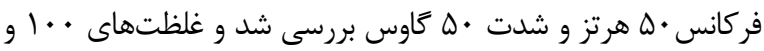

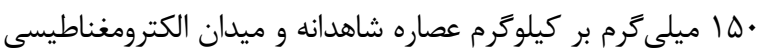

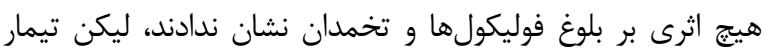

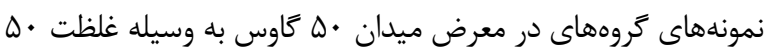

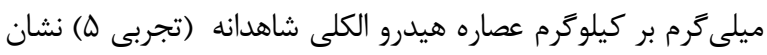

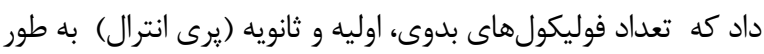

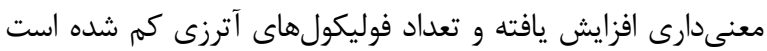
. ( )

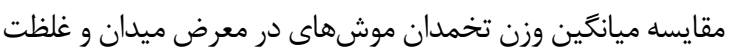

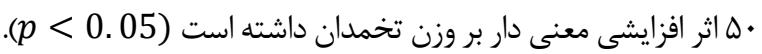
بررسى هاى هورمونى در كروه تجربى له (اثر توام ميدان •له كاوس

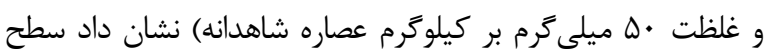

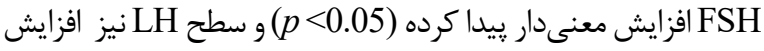

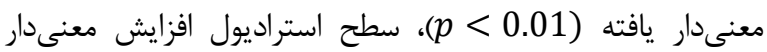
داشته (0.01 > p p ) و سطح يروزسترون كاهش معنى دار داشته است

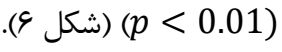

استفاده روز افزون از دستگاههاى مولد امواج الكترومغناطيسى، توجه

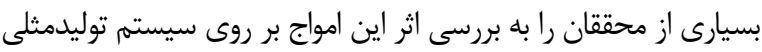

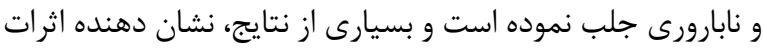

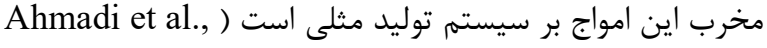

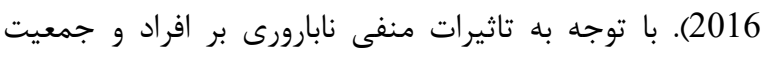

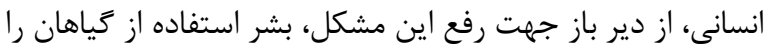

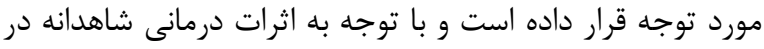

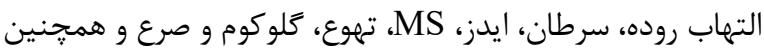

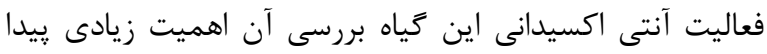

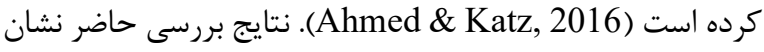

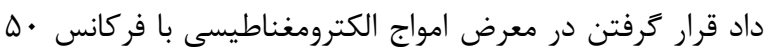

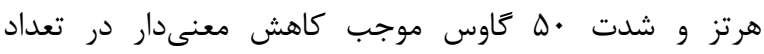

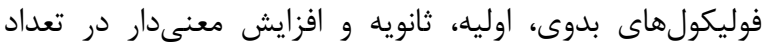

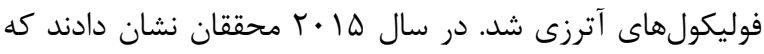

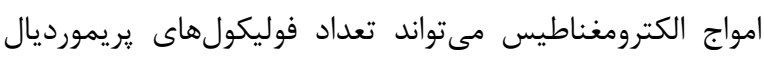
تخمدان رت را كاهش دهد (Bakacak et al., 2015).
شاهدانه (تجربى F) كاهش معنى دار تعداد فوليكولهاى ابتدايى و

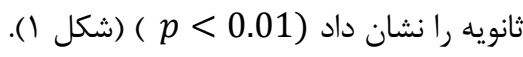

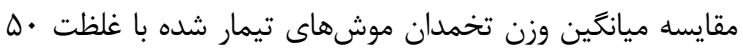

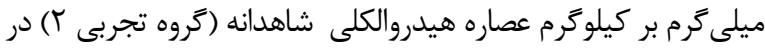

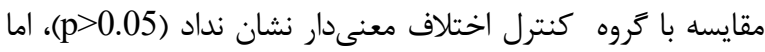

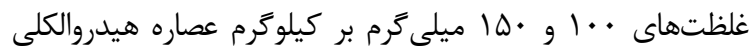

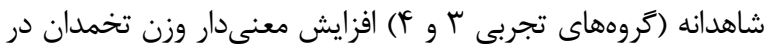

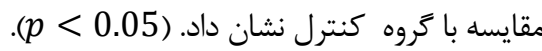

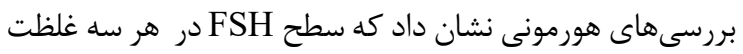

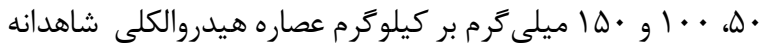

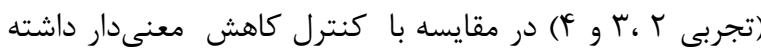

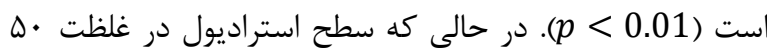
ميلى

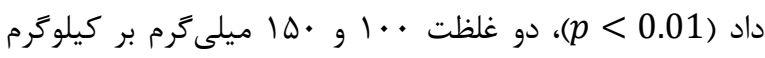
كاهش معنى دارى را در ميزان استراديول در مقايسه با كنترل نشان

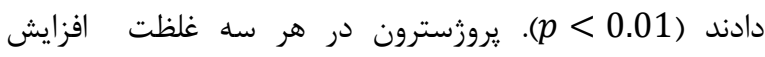

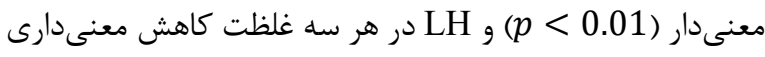

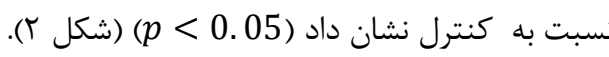

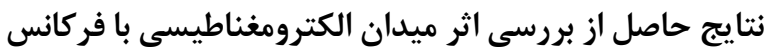

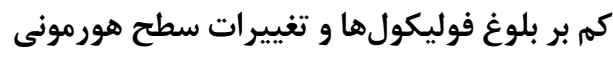

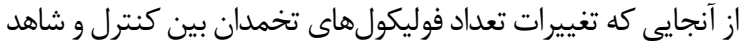

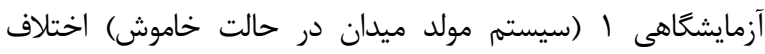

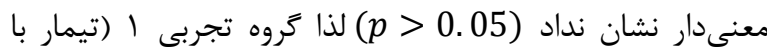

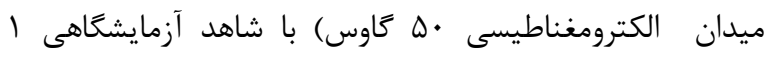
مقايسه شد.

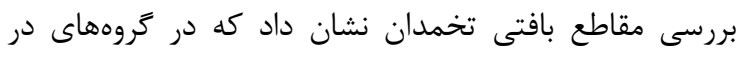

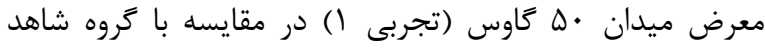

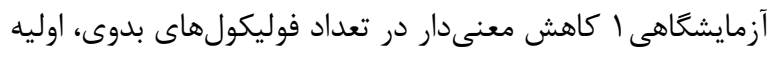

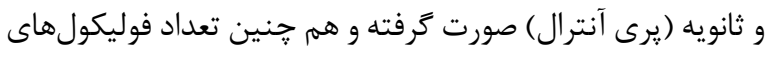

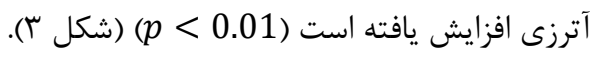

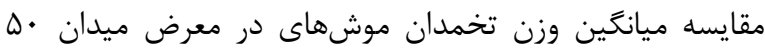

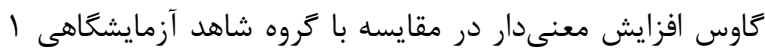

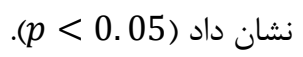

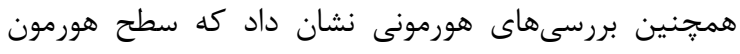
LH ، FSH

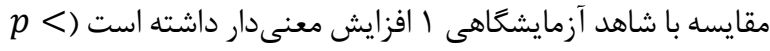
0.01). در حالى كه سطح يروزسترون اختلاف معنى دارى نشان إندان

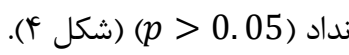




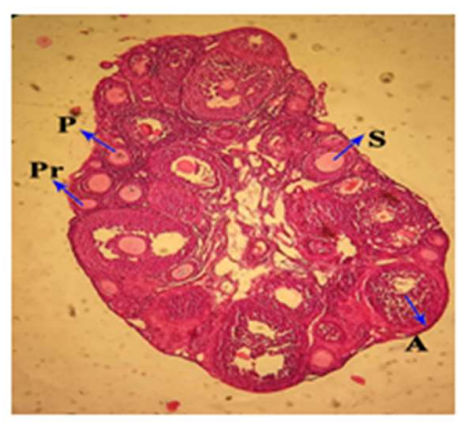

A

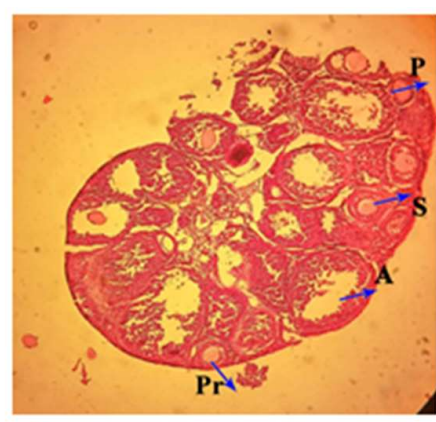

B

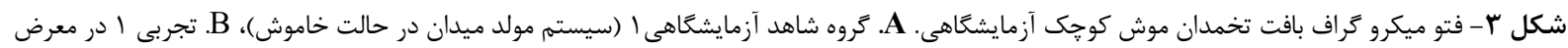

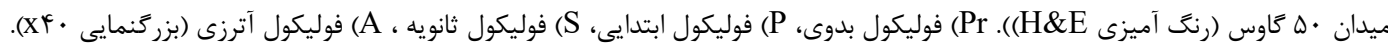

Fig. 3. Photo micrograph of ovarian tissue. A: sham 1 (field off), B. experimental 1 exposed to a field of 50 Gauss (H \& E staining)). Pr) Primordial follicle, P) Primary follicle, S) Secondary follicle, A) Atresia follicle (zoom in X40).

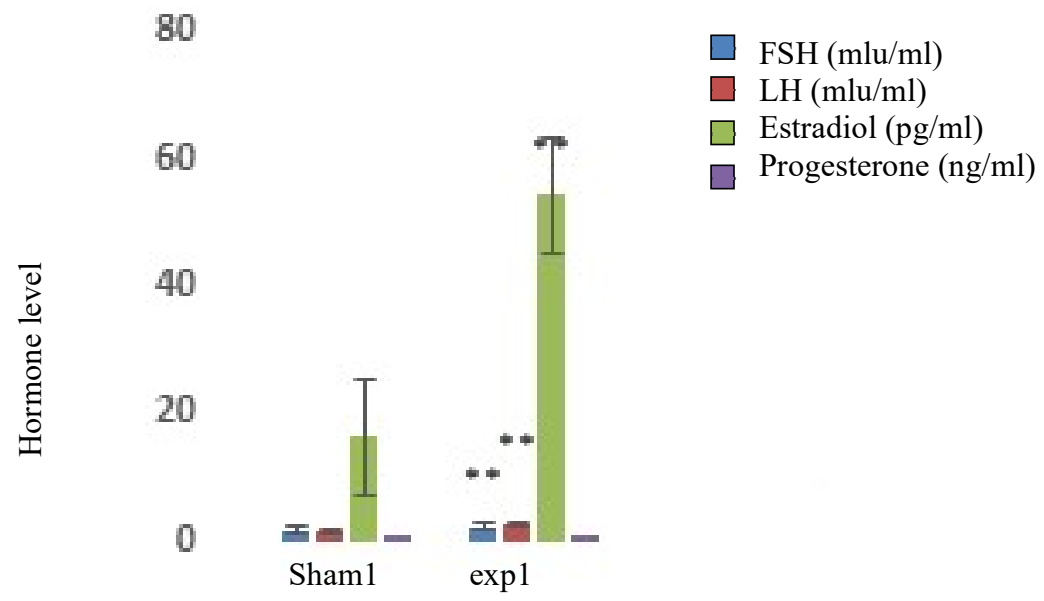

Experimental groups

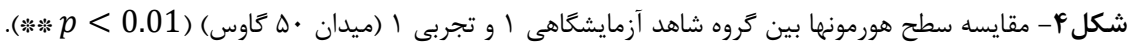

Fig. 4. Comparison of the steroid hormone levels among sham1 and experimental 1 (field of 50 Gauss) (** p < 0.01 ).

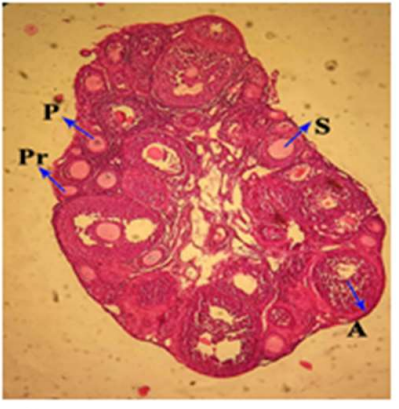

A

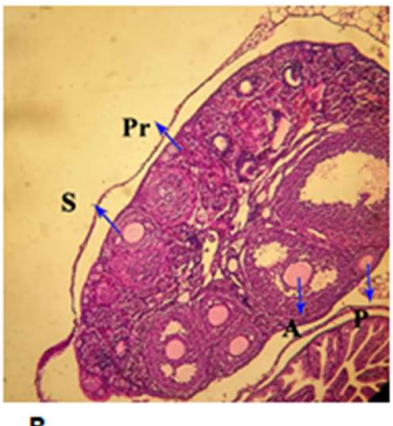

B

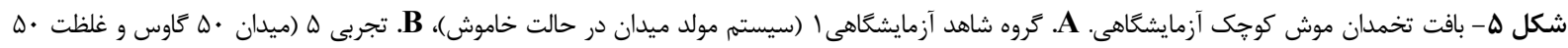
ميلى

Fig. 5. Photo micrograph of ovarian tissue. A. sham 1 (field off), B. experimental 5 exposed to a field of 50 Gauss and treated with concentrations $50 \mathrm{mg} / \mathrm{kg}$ of Cannabis extract (H \& E staining). Pr: Primordial follicle, P: Primary follicle, S: Secondary follicle, A: Atresia follicle (zoom in x40). 
100

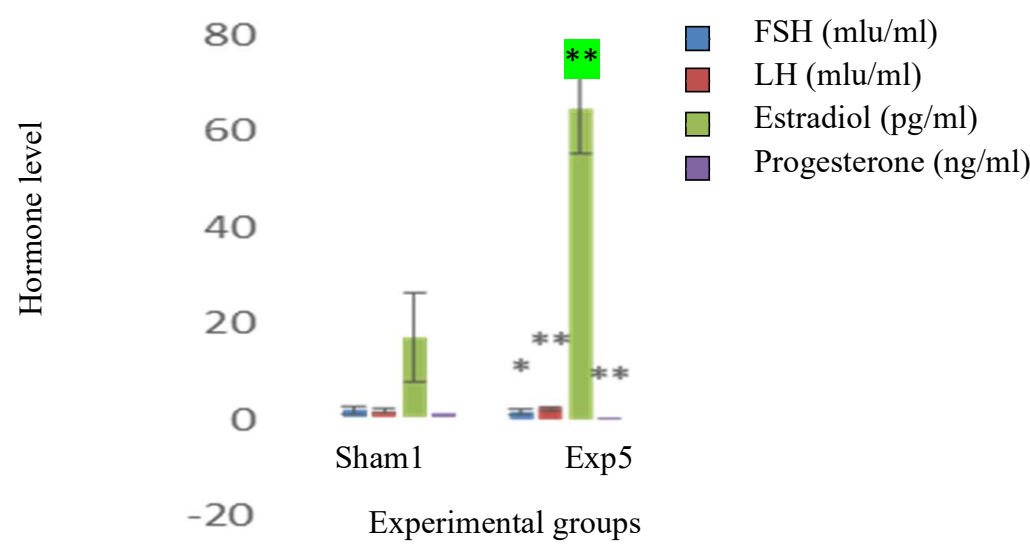

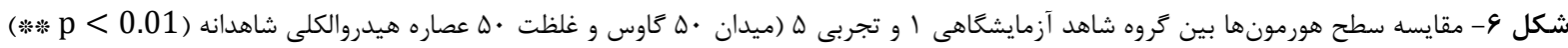
. $(* \mathrm{p}<0.05)$

Fig. 6. Comparison of the steroid hormone levels among sham $1 \&$ experimental 5 (field of 50 Gauss treated with concentration of $50 \mathrm{mg} / \mathrm{kg}$ of Cannabis extract $(* * \mathrm{p}<0.01)(* \mathrm{p}<0.05)$.

(Alghanimi, 2017 نتايج مطالعات قبلى با مطالعه حاضر در

ارتباط با سطح هورمونهاى LH و أستر استراديول همراستا است

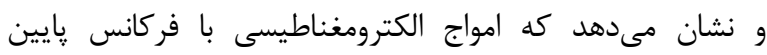

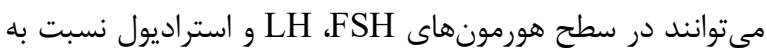

كروه كنترل افزايش معنى دار ايجاد كنند.

نتايج بررسى حاضر مشخص كرد قرار گرفتن در معرض مدرد اموراج

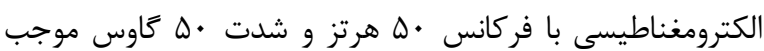

افزايش معنى دار در وزن تخمدانهاى در معرض اين امواج نسبت به به

$$
\text { كروه كنترل شد. }
$$

در مطالعهاى مشخص شد كه تيمار با امواج الكترومغناطيسى موجب لشد

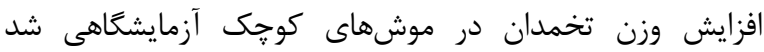

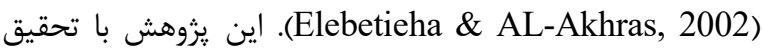

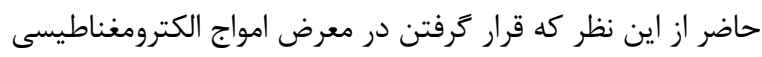
با فركانس • له هرتز و شدت • ه كاوس موجب افزايش معنى دار در

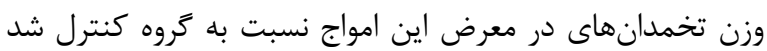

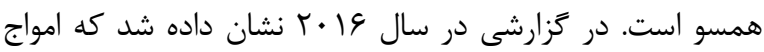

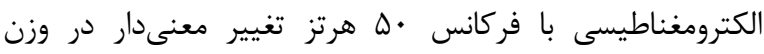

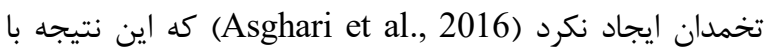
تحقيق حاضر هم راستا نيست زيرا در مطالعه حاضر نشان داده شد إدان كه قرار گرفتن در معرض امواج الكترومغناطيسى با فر كانس • •ه هرتز رئز و شدت •ه كاوس موجب افزايش معنى دار در وزن تخمدانهاى در معرض اين امواج نسبت به گروه كنترل شد.
در مطالعهاى كه در سال 19 • ب صورت گرفت مشخص شد كه امواج الكترومغناطيسى موجب تاثير منفى در روند تكوين فوليكولها در رتهاى ماده شدند و در آنها آترزى فوليكولهاى تخمدان دئ ديده

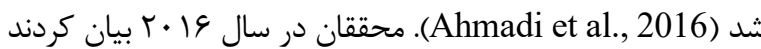
كه امواج الكترومغناطيس موجب كاهش تعداد فوليكولها مىشود، همجنين قرار زرفتن طولانى مدت در معرض اين امواج موجب اثر موني زيان آورى بر بافت گناد مى گردد (Khaki et al., 2016). نتايج يزوهش حاضر با نتايج مطالعات قبلى همسو است و مويد اين مطلب است كه امواج الكترومغناطيسى با فركانس يانس هيايين مىتوانند در تكوين فوليكولها اختلال ايجاد كنند و از تعداد فوليكولهاى بدوى، اوليه، ثانويه يا يرى آنترال كاسته و تعداد

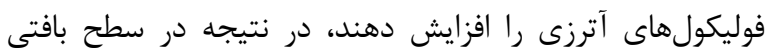

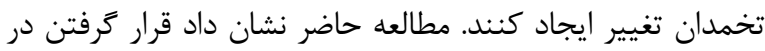

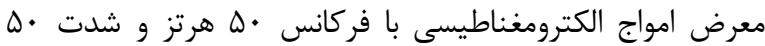
كاوس موجب افزايش معنى معار سطح هورمونهاى FSH، LH و

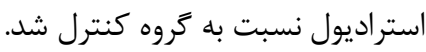
در زَارشى در اثر تيمار با امواج موبايل نشان داده شد كه سطح

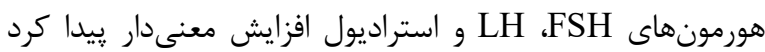

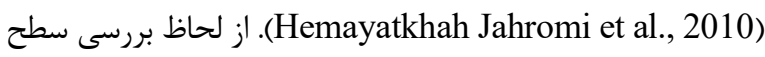
هورمونى نشان داده شده است كه در اثر امواج موبايل سطح

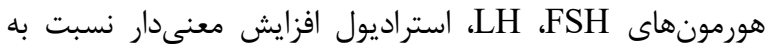
آنهايى كه در معرض اين امواج نبودند، يِيدا كرد ) Najem \& 
بررسى قرار دادند و متوجه شدند كه اين عصاره موجب كاهش ميزان

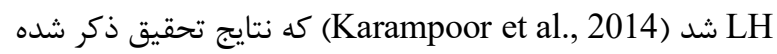

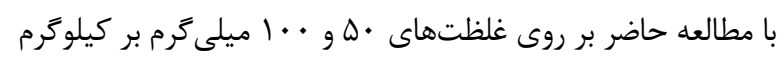

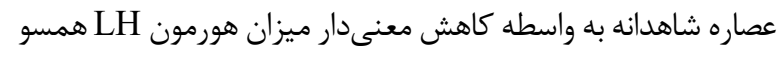

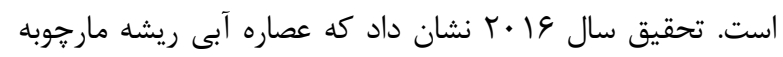

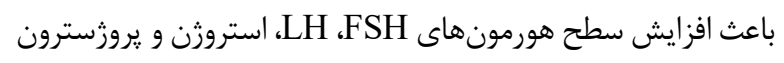

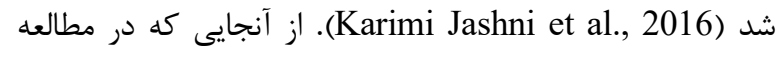

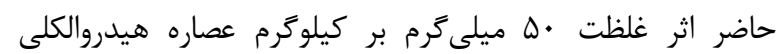

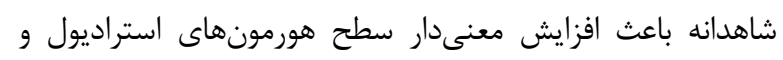

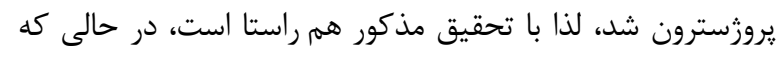

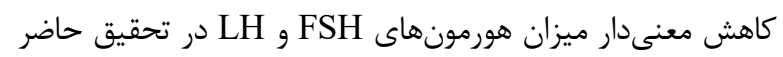

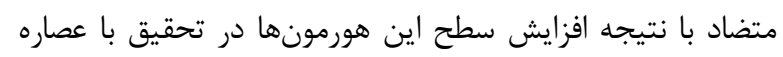

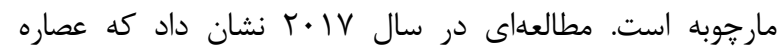

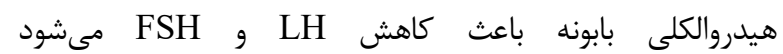
(Mirzakhani \& Hosseini, 2017)

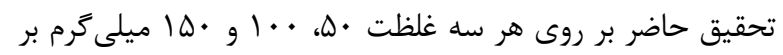

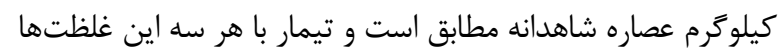

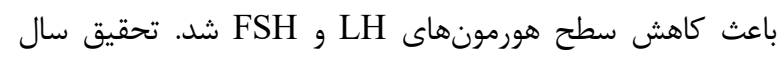

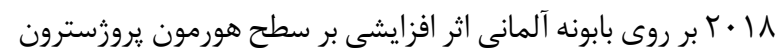

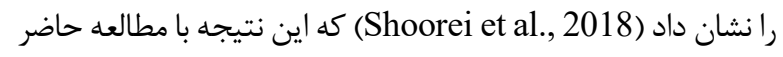

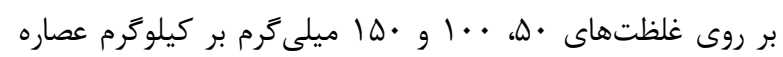

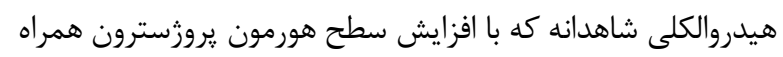

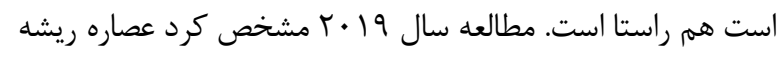

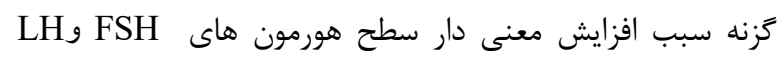
شد(Esfadeh et al., 2019)، در حالى كه كاهش معنى سنى دار ميزان هورمونهاى FSH و LH در تحقيق حاضر متضاد با نتيجه تحقيق مذكور است.

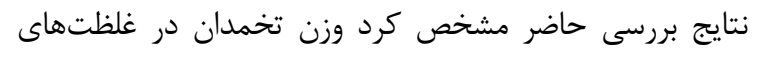

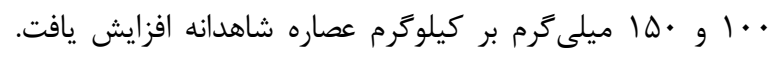

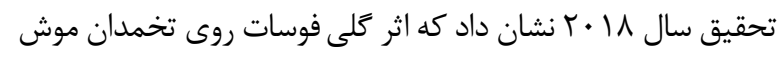

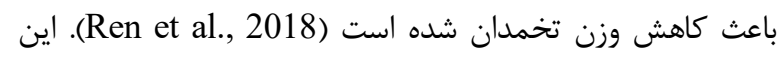

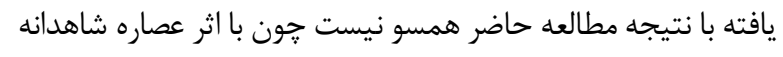

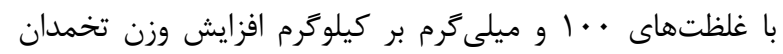

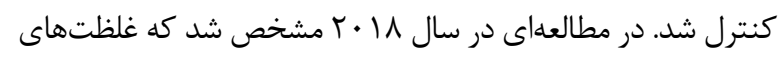

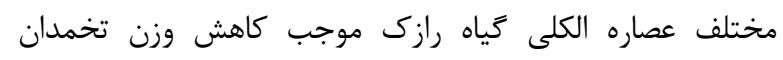
Parandin \& Yousofvand, ) موشهاى ماده تيمار شده ترديد

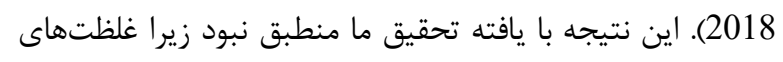

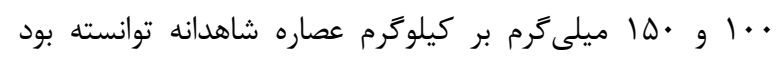

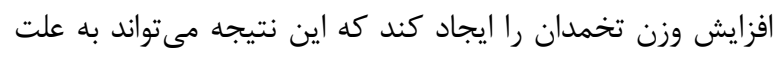
افزايش حجم فوليكولها و تعداد سلولها در تخمدان باشد.
نتايج يزوهش حاضر نشان داد غلظت •Dه ميلى

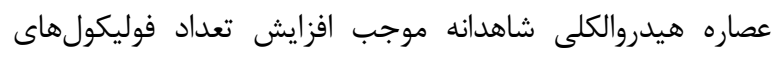

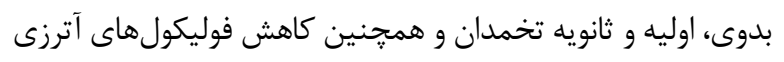

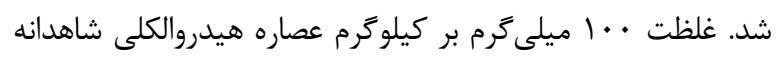

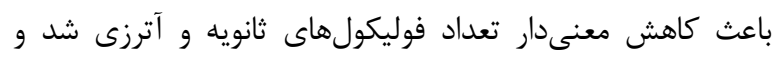

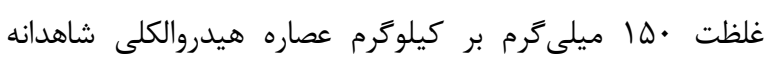

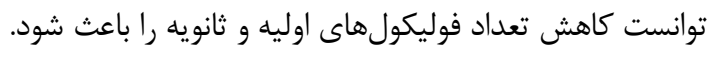

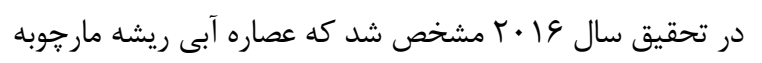

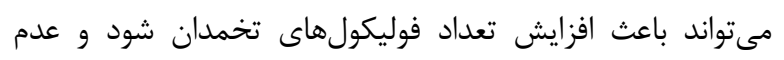

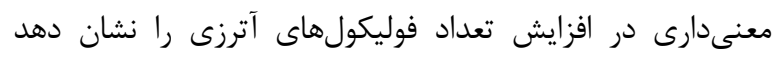

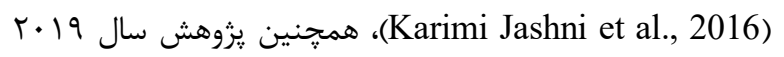

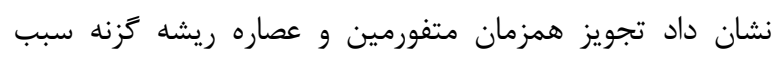

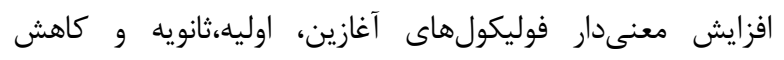

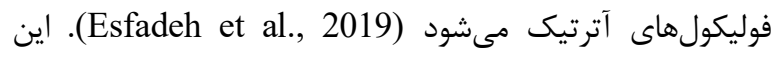

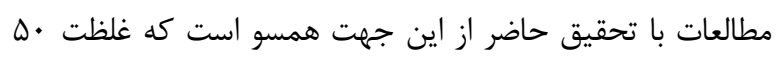

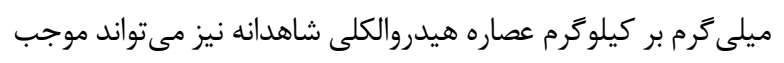

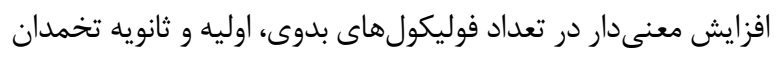

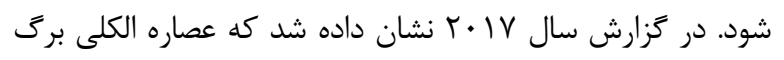

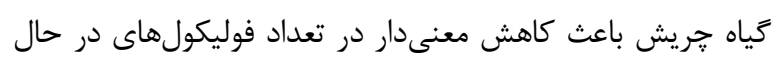

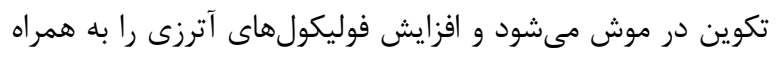

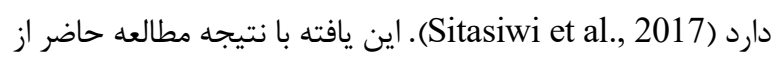

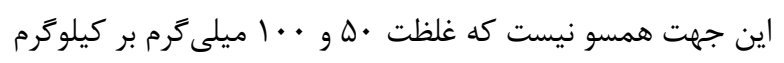

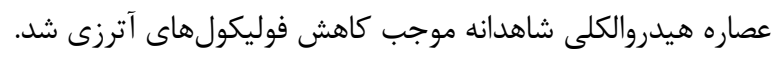
مطالعه حاضر مشخص كرد غلظت • ه ميلى گرم بر كيلو كرم عصاره

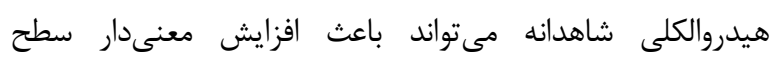

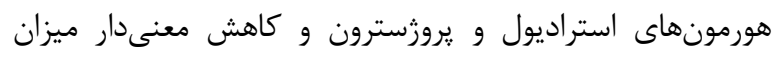

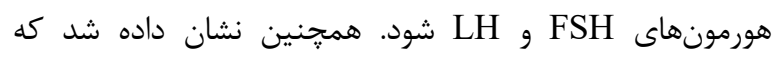

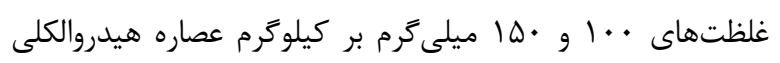

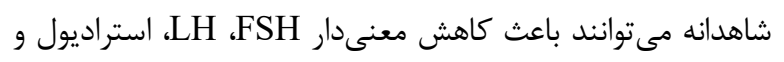
افزايش يروزسترون شوند.

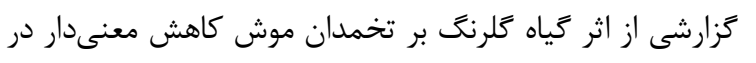

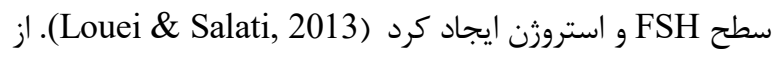

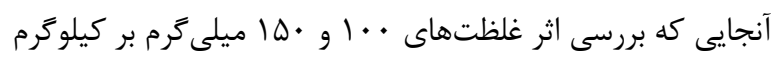

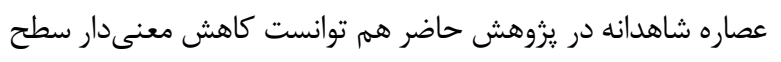

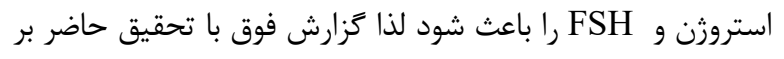

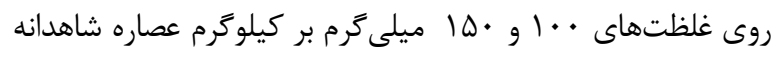

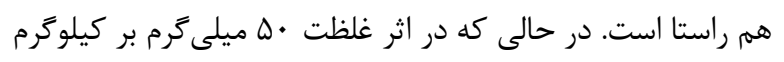

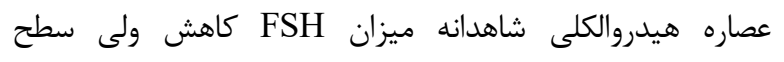

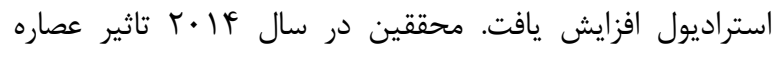

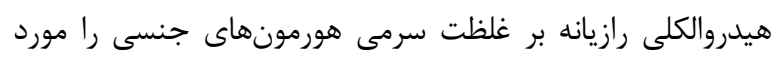


نتيجه در افزايش معنى دار سطح LH با خزارش حاضر در اثر كاربرد

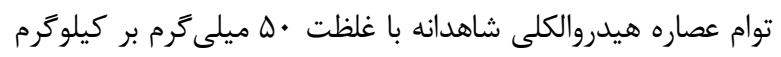
و امواج با فر كانس •له هرتز و شدت •له كاوس همسو است.

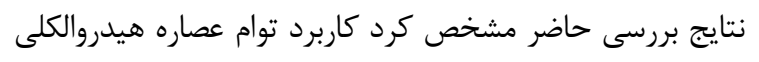

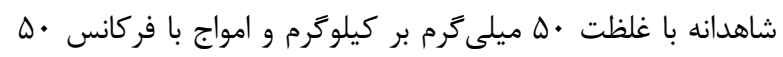

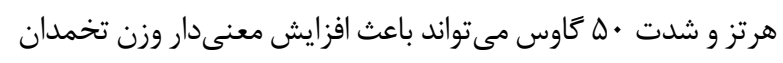

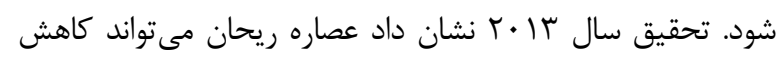

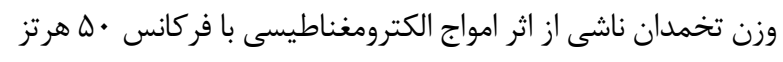

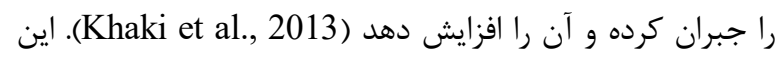

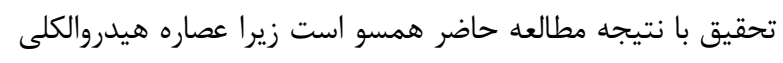

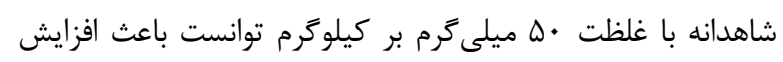

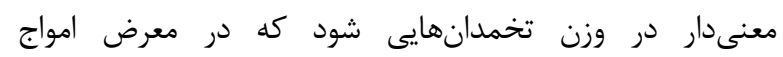

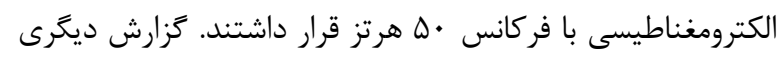

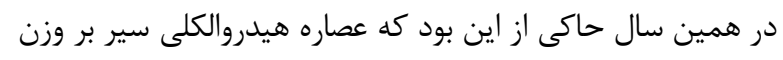

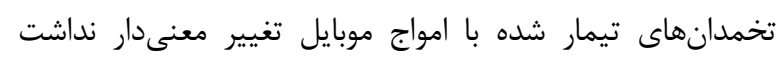

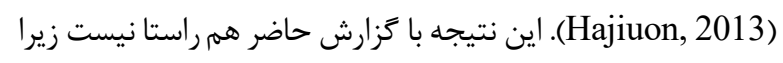

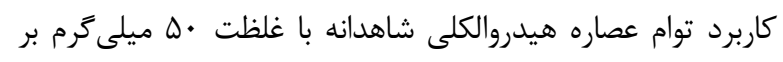

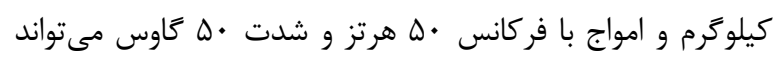

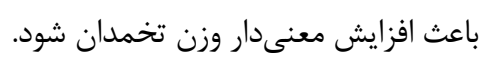

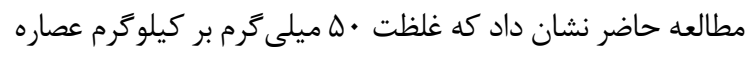

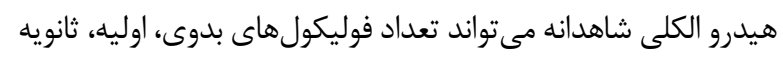

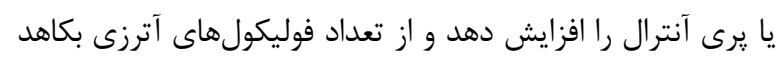

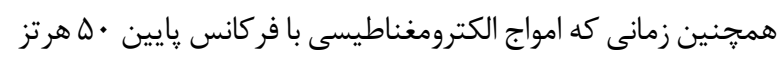

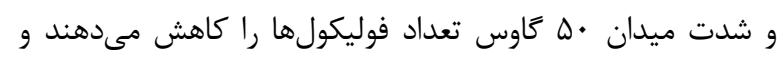

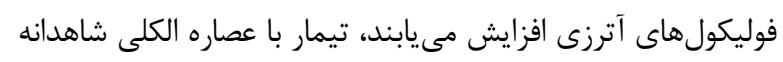

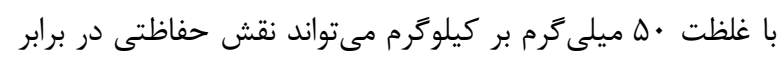

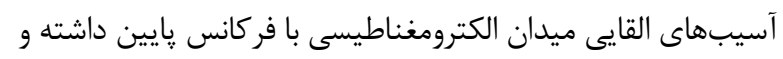

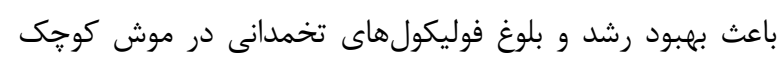

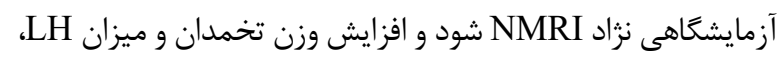
FSH

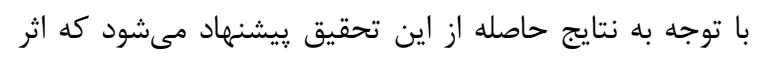

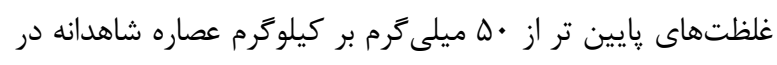

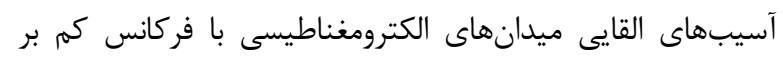
تعداد فوليكولهاى تخمدان و سطح هورمونهاى استروئيدى مورد

$$
\text { بررسى قرار كيرد. }
$$$$
\text { سياسگَزارى }
$$

بدين وسيله از كارشناسان مركز تحقيقاتى تكوين جانورى

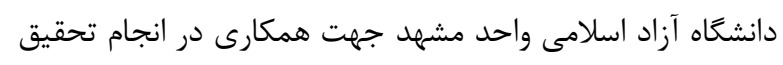
حاضر تشكر مىنماييم.
در يزوهش حاضر اثر توام عصاره هيدروالكلى شاهدانه و امواج با

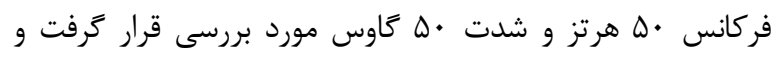
مشخص شد غلظت •ه ميلى كرم بر كيلوكرم عصاره كياه شاهدانه

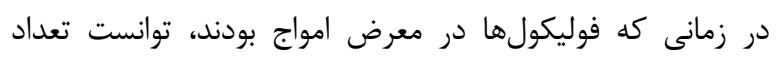

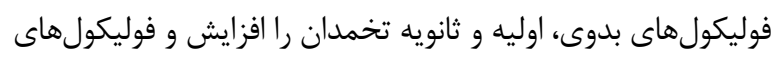

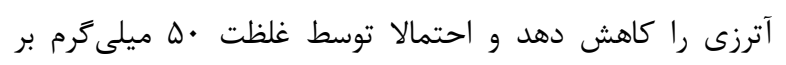

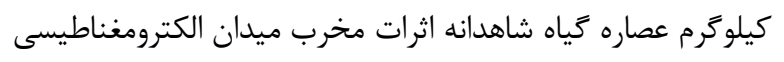

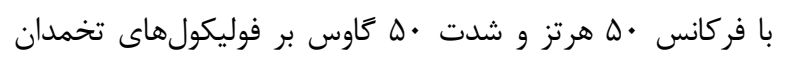

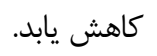
جندين مطالعه عنوان كردهاند كه جوانهها، دانها و برك ابنهاى

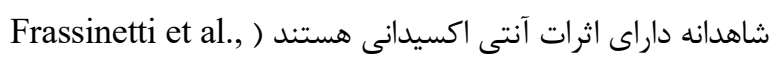

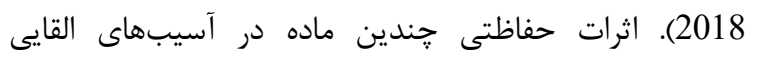

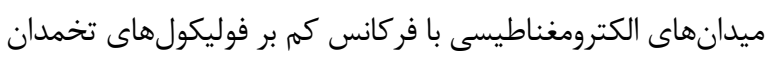

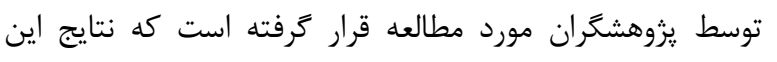
تحقيقات نشان داد كه توسط اثر آنتى اكسيدانى ويتامين E ع عران عصاره

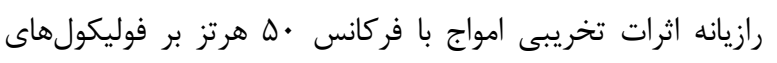

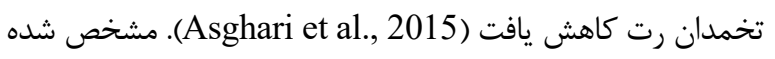

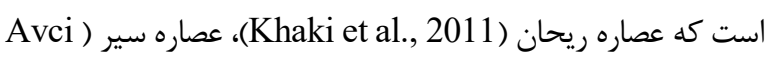

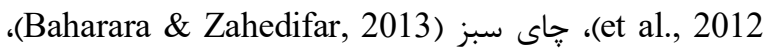

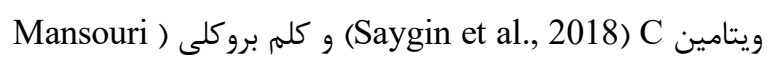
نيز نقش حفاظتى در برابر ميدانهاى (et al., 2019 الكترومغناطيسى ايفا مى كنند. تمام اين مطالعات از اين نظر با تحقيق حاضر در يك رينا راستا هستند

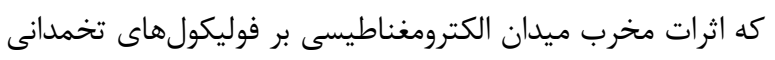

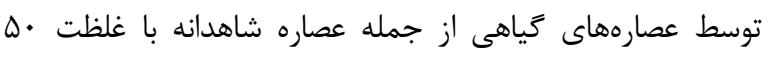
ميلى

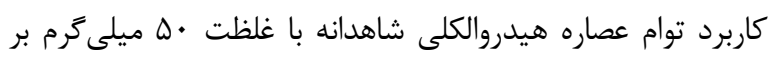

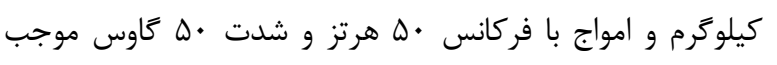

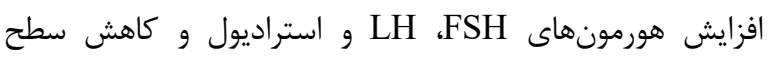
هورمون يروزسترون شد. در كزارشى كه عصاره هيدروالكلى سير را بر بافت تخمدان موش

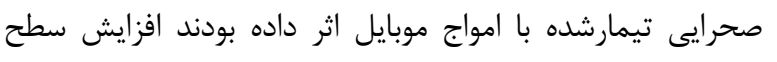
مروزسترون مشاهده شد (Hajiuon, 2013). اين تحقيق با نتيجه مطالعه حاضر كه كاهش ميزان يروزسترون در اثر كاربرد توام ميدان

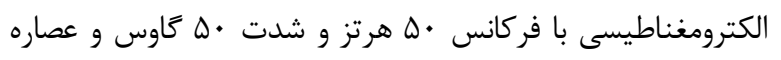

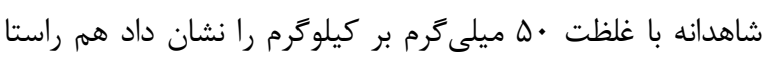

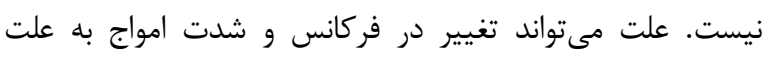

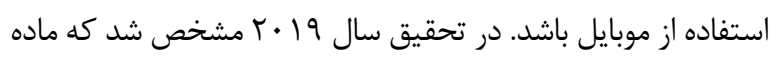

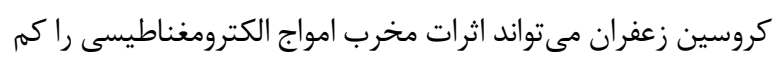

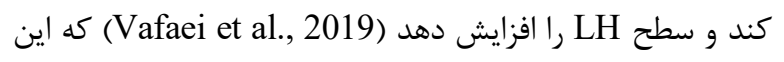




\section{REFERENCES}

Ahmadi, S.S., Khaki, A.A., Ainehchi, N., Alihemmati, A., Khatooni, A.A., Khaki, A. \& Asghari, A. 2016. Effect of non-ionizing electromagnetic field on the alteration of ovarian follicles in rats. Electronic Physician Journal 8: 2168-2174.

Ahmed, W. \& Katz, S. 2016. Therapeutic use of cannabis in inflammatory bowel disease. Gastroenterology \& Hepatology 12: 668-679.

Asghari, A., Khaki, A.A., \& Khaki, A. 2016. A review on electromagnetic fields (EMFs) and the reproductive system. Electron Physician 8: 2655-2662.

Asghari, A., Montaseri, A. \& Khaki, A.A. 2015. A study of the protective effects of vitamin $\mathrm{E}$ and fennel extract on mitochondria changes in mice ovary due to electromagnetic field exposure.Crescent Journal of Medical and Biological Sciences 2: 10-13.

Avci, B., Akar, A., Bilgici, B. \& Tuncel, O.K. 2012. Oxidative stress induced by $1.8 \mathrm{GHz}$ radio frequency electromagnetic radiation and effects of garlic extract in rats. International Journal of Radiation Biology 88: 799-805.

Baharara, J. \& Zahedifar, Z. 2013. Effect of green tea in decreasing electromagnetic waves damage. Zahedan Journal of Research in Medical Sciences 17: 29-34.

Baharara, J., Parivar, K., Oryan, Sh. \& Ashraf, A.R. 2006. Effects of low frequency electromagnetic fields on gonads and fertility of female Balb/c mouse. Journal of Arak University Medical Sciences 9: 1-11. (In Persian).

Baharara, J., Ramezani, T., Saghiri, N. \& Salek F. 2019. nvestigating the apoptotic effects of silver nanoparticles coated with Achillea biebersteinii extract on A2780 ovarian cancer cells. Nova Biologica Reperta 6: 140-147.

Bakacak, M., Bostanci, M.S., Attar, R., Yildirim, O.K., Yildirim, G., Bakacak, Z., Sayar, H. \& Han, A. 2015. The effects of electromagnetic fields on the number of ovarian primordial follicles: An experimental study. Kaohsiung Journal of Medical Sciences 31: 287-292.

Campen, K.A., McNatty, K.P. \& Pitman, J.L. 2017. A protective role of cumulus cells after short-term exposure of rat cumulus cell-oocyte complexes to lifestyle or environmental contaminants. Reproductive Toxicology 69: 19-33.

Elebetieha, A. \& AL-Akhras, M. 2002. Long-term exposure of male and female mice to $50 \mathrm{~Hz}$ mag- netic field: effects on fertility. Bioelectromagnetics 23: 168-172.

Farrokhyar, S., Baharara, J., Namvar, F., Behnam Rasoli, M \& Ramezani, T. 2015. Evaluation effect of methanol extract of brittle stars Persion Gulf in vitro. Quarterly Journal of Biological Sciences 8: 61-68.

Frassinetti, S., Moccia, E., Caltavuturo, L., Gabriele, M., Longo, V., Bellani, L., Giorgi, G. \& Giorgetti, L. 2018. Nutraceutical potential of hemp (Cannabis sativa L.) seeds and sprouts. Food Chemistry 262: 56-66.

Esfadeh, H., Mirabolghasemi, G., Azarnia M. 2019. The joint effect of hydro-alcoholic extract of nettle root and metformin on ovarian tissue of diabetic model of Wistar rat. Nova Biologica Reperta 6: 131-139. (In Persian).

Hajiuon, B. 2013. Effects of cell phone radiation on estrogen and progesterone levels and ovarian changes in rats treated with garlic (Allium sativum L.) hydroalcoholic extract. Journal of Herbal Drugs 4: 81-88.
Hemayatkhah Jahromi, V., Fatahi, E., Nazari, M., Jowhary, H. \& Kargar, H. 2010. Study on the effects of mobile phones waves on the number of pvarian follicles and level of FSH, LH, estrogen and progestrone hormones in adult rats. Tissue and Cell 1:27-34. (In Persian).

Kaboli Kafshgiri, S., Parivar, K., Baharara, J., Hayati Roodbari, N. \& Kerachian, M.A. 2017. Comparison the effect of movento, a chemical pesticide, with chitosan a biologic pesticide, on female reproductive system in Balb/C mice. Nova Biologica Reperta 3: 279-287. (In Persian).

Karampoor, P., Azarnia, M., Mirabolghasemi, G. \& Alizadeh, F. 2014. The effect of hydroalcoholic extract of Fennel (Foeniculum vulgare) seed on serum levels of sexual hormones in female wistar rats with Polycystic Ovarian Syndrome (PCOS). Journal of Arak University Medical Sciences 17: 70-78. (In Persian).

Karimi Jashni, H., Kargar Jahromi, H. \& Khabbaz Kherameh, Z. 2016. Effects of aqueous extract from Asparagus officinalis L. roots on hypothalamic-pituitarygonadal axis hormone levels and the number of ovarian follicles in adult rats. International Journal of Reproductive BioMedicine 14: 75-80.

Khaki, A.A., Khaki, A.y. and Ahmadi, S.Sh. 2016. The effect of non-ionizing electromagnetic field with a frequency of $50 \mathrm{~Hz}$ in Rat ovary: A transmission electron microscopy study. International Journal of Reproductive BioMedicine 14: 125-132. (In Persian).

Khaki, A., Khaki, A.A. \& Zahedi, A. 2013. Effect of Ocimum basilicum on Ovary tissue Apoptosis after exposed with extremely low frequency electromagnetic fields (ELFEMF) in Rats. Life Science Journal 10: 1-5.

Khaki, A., Fathizad, F., Nouri, M. \& Khaki, A.A. 2011. Effect of Ocimum basilicum on apoptosis in testis of rats after exposure to electromagnetic field.- African Journal of. Pharmacy and Pharmacology 5: 1534-1537. (In Persian).

Khaleghi, Kh., Rajaei, F., Javadi, A \& Abedpour, N. 2014. The effect of PMSG and hCG on the ovarian follicles in NMRI strain mice. Qom University of Medical Sciences Journal 8: 1-10. (In Persian).

Lopez-Cardona, A.P., Sanchez-Calabuig, M.J., BeltranBrena, P., Agirregoitia, N., Rizos, D., Agirregoitia, E \& Gutierrez-Adan, A. 2016. Exocannabinoids effect on in vitro bovine oocyte maturation via activation of $\mathrm{KT}$ and ERK1/2. Reproduction 152: 603-612.

Louei Monfared, A. \& Salati, A.P. 2013. Effects of Carthamus tinctorius L. on the ovarian histomorphology and the female reproductive hormones in mice. Avicenna Journal of Phytomedicine 3: 171-177.

Mansouri, E., Keshtkar, A., Khaki, A., Keshtkar, E. \& Khaki, A. 2019. Effects of extremely low frequency electromagnetic fields and simultaneous treatment with Allium cepa on biochemical parameters and ultrastructure of ovarian tissues of rats. Iranian Journal of Medical Physics 16: 158-165.

Mirzakhani, Z. \& Hosseini, S.E. 2017. Effects of chamomile hydro- alcoholic extract (Matricaria chamomilla) on the aborted fetuses, serum sex hormones and ovarian follicles in adult female rats. Journal of Ardabil University of Medical Sciences 17: 22-31. (In Persian).

Najem, N.A. \& Alghanimi, Y.Kh. 2017. Effect of GMS (Towers and Mobil radiation) on reproductive hormones in 
males. International Journal of ChemTech Research 10: 652-654.

Nayebi, Sh., Kakeshpour, T., Hasanvand, A., Nadri, M. \& Rashidi Monfares, S. 2013. Composition of volatile compounds of extract of Ammi majus from Iran by GCMS. Journal of Sciences, Islamic Republic of Iran 24: 335338.

Parandin, R. \& Yousofvand, N. 2018. Effects of perinatal exposure to alcoholic extract of hops (Humulus lupulus) flowers on sexual puberty and some reproductive parameters in female mice. Razi Journal of Medical Sciences 25: 10-20. (In Persian).

Ren, X., Li, R., Liu, J., Huang, K., Wu, S., Li, Y. \& Li, Ch. 2018. Effects of glyphosate on the ovarian function of pregnant mice, the secretion of hormones and the sex ratio of their fetuses. Environmental Pollution 243: 833-841.

Saygin, M., Ozmen, O., Erol, O, Ellidag, H.Y., Ilhan, I., Aslankoc, R. 2018. The impact of electromagnetic radiation $(2.45 \mathrm{GHz}, \mathrm{Wi}-\mathrm{Fi})$ on the female reproductive system: The role of vitamin C. Toxicology \& Industrial Health 34: 620-630.
Shoorei, H., Khaki, A. \& Abbas Raza, S.H. 2018. Effects of Matricaria chamomilla extract on growth and maturation of isolated mouse ovarian follicles in a three-dimensional culture system. Chinese Medical Journal 131: 218-225.

Sitasiwi, A.J., Isdadiyanto, S. \& Mardiati, S.M. 2017. The Estradiol 17- $\beta$ Concentration in Mice after Treated with Ethanolic Leaf Extract of Azadirachta indica (Neem). AIP Conference Proceedings 1844: 2-8.

Tehranipour, M., Kehtarpour, M., Javadmoosavi, B.Z. \& Mahdavi-Shahri, N. 2012. Evaluation of Cannabis sativa leaves aquatic extract effect on triple regions of hippocampus neuronal density in male rats. Journal of Shahrekord University of Medical Sciences 14: 20-27. (In Persian).

Vafaei, Sh., Motejaded, F. \& Ebrahimzadeh- bideskan, A. 2019. Protective effect of crocin on electromagnetic fieldinduced testicular damage and heat shock protein A2 expression in male BALB/c mice. Iranian Journal of Basic Medical Sciences 23: 102-110.

Wdowiak, A., Mazurek, P.A. \& Bojar, I. 2017. Effect of electromagnetic waves on human reproduction. Annals of Agricultural and Environmental Medicine 24: 13-18.

How to cite this article:

Mehrbakhsh, A., Baharara, J., Zafar Balanejad, S. \& Kerachian, M.A. 2020. Effect of Cannabis sativa extract on induced damage to electromagnetic fields on ovarian follicle maturation and hormonal surface changes in mice. Nova Bioloica Reperta 7: 267-277. (In Persian).

$$
\begin{aligned}
& \text { مهربخش، ا.، بهار آرا، ج.، ظفر بالانزاد، س. و كراجيان، م. ا. و9جا. اثر عصاره شاهدانه در آسيب القايى ميدانهاى الكترومغناطيسى بر بلوغ فوليكولهاى }
\end{aligned}
$$

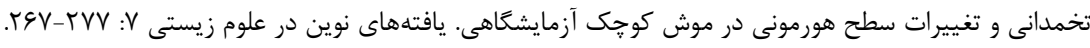

